\title{
Actual Device Evaluated Evaluation Method
}

National Cancer Institute

\section{Source}

National Cancer Institute. Actual Device Evaluated Evaluation Method. NCI Thesaurus. Code $C 91896$.

The investigation employed relevant empirical testing of the actual device suspected in the reported adverse event in order to establish their functional and other properties and to identify possible causes for the adverse event. Relevant testing would typically be based on test methods used for evaluating safety and performance as described in the latest relevant standards. 